\title{
Elemental selenium particles at nano-size (Nano-Se) are more toxic to Medaka (Oryzias latipes) as a consequence of hyper-accumulation of selenium: A comparison with sodium selenite
}

\author{
Hongcheng Li $^{a}$, Jinsong Zhang ${ }^{b}$, Thanh Wang ${ }^{a}$, Wenru Luo ${ }^{a}$, Qunfang Zhou ${ }^{a}$, Guibin Jiang ${ }^{a, *}$ \\ a State Key Laboratory of Environmental Chemistry and Ecotoxicology, Research Center for Eco-Environmental Sciences, Chinese Academy of Sciences, \\ P.O. Box 2871, Beijing 100085, China \\ ${ }^{\mathrm{b}}$ School of Chemistry and Material Science, University of Science and Technology of China, Hefei 230052, China
}

\section{A R T I C L E I N F O}

Article history:

Received 1 May 2008

Received in revised form 7 July 2008

Accepted 14 July 2008

\section{Keywords:}

Nano-Se

Selenite

Medaka

Nanotoxicology

Hyper-accumulation

\begin{abstract}
A B S T R A C T
Recent studies have shown that elemental selenium particles at nano-size (Nano-Se) exhibited comparable bioavailability and less toxicity in mice and rats when compared to sodium selenite, selenomethinine and methylselenocysteine. However, little is known about the toxicity profile of Nano-Se in aquatic animals. In the present study, toxicities of Nano-Se and selenite in selenium-sufficient Medaka fish were compared. Selenium bioaccumulation and subsequent clearance in fish livers, gills, muscles and whole bodies were examined after 10 days of exposure to Nano-Se and selenite ( $100 \mu \mathrm{g} \mathrm{Se} / \mathrm{L})$ and again after 7 days of depuration. Both forms of selenium exposure effectively increased selenium concentrations in the investigated tissues. Surprisingly, Nano-Se was found to be more hyper-accumulated in the liver compared to selenite with differences as high as sixfold. Selenium clearance of both Nano-Se and selenite occurred at similar ratios in whole bodies and muscles but was not rapidly cleared from livers and gills. Nano-Se exhibited strong toxicity for Medaka with an approximately fivefold difference in terms of $\mathrm{LC}_{50}$ compared to selenite. Nano-Se also caused larger effects on oxidative stress, most likely due to more hyper-accumulation of selenium in liver. The present study suggests that toxicity of nanoparticles can largely vary between different species and concludes that the evaluation of nanotoxicology should be carried out on a case-by-case basis.
\end{abstract}

(c) 2008 Published by Elsevier B.V.

\section{Introduction}

Selenium (Se), as an essential micronutrient for animals and humans (Klasing, 1998; Eisler, 2000), plays important roles in antioxidant defense systems, regulation of thyroid hormone metabolism, and cell growth (Patching and Gardiner, 1999). However, levels of accumulated selenium in the body that exceed nutritional requirements could cause large harm to organisms (Hilton et al., 1980). Some studies have reported that excessive intake of selenium could lead to gastrointestinal disturbances (vomiting, diarrhea, etc.), hair and nail changes, and neurologic manifestations including acroparesthesias, weakness, convulsions, and decreased cognitive function (Clark et al., 1996; Gasmi et al., 1997). Within the past few decades, there has been an increased emphasis in understanding the aquatic toxicology of waterborne Se exposure to develop national water quality criteria for Se. Although

\footnotetext{
* Corresponding author. Fax: +86 1062849179

E-mail address: gbjiang@rcees.ac.cn (G. Jiang).
}

extensive research on Se toxicity has been conducted, the action modes of Se at the cellular and molecular levels are not yet fully understood.

It is known that the toxicity of Se depends not only on the chemical form and body burden but also on a variety of other factors such as the type of species, physiological state, nutrition and dietary interactions, and route of administration. Elemental Se powder in the redox state of zero is generally considered as biologically inert. The rapid development of nanotechnology holds great promises for application in medicinal and nutritional science because materials at the nano-scale have been found to exhibit novel properties different to those at micro-scale and bulk materials (Albrecht et al., 2006). With bovine albumin protein as a disperser, nano-red elemental selenium atoms by reducing selenite with reduced glutathione (GSH) can aggregate into particles in the sizes of 20-60 nm (Nano-Se). Previous researches reported that NanoSe possessed comparable efficiency to selenite, selenomethionine, and methylselenocysteine in upregulating selenoenzymes in mice and rats (Zhang et al., 2005,2008; Wang et al., 2007), but exhibited dramatically decreased acute toxicity (Zhang et al., 2001). At 
present, very little is known about the toxicological profiles of Nano-Se in aquatic organisms. Our studies herein were carried out to estimate the toxicities of inorganic selenite $\left(\mathrm{Na}_{2} \mathrm{SeO}_{3}\right)$ and Nano-Se to Medaka fish, based on examining bioaccumulation and clearance of both Se forms in fish bodies and tissues.

\section{Materials and methods}

\subsection{Chemicals}

Nano-Se $(36 \mathrm{~nm})$ was synthesized as described previously (Zhang et al., 2001). Sodium selenite $\left(\mathrm{Na}_{2} \mathrm{SeO}_{3}, 98 \%\right.$ purity) was purchased from Beijing Zhonglian Chemical Company (Beijing, China). Commercial kits of glutathione peroxidase (GPx), superoxide dismutase (SOD), and GSH were purchased from Nanjing Jiancheng Bioengineering Institute (NJBI, China). Nitric acid (Merck, Germany) and peroxide acid (Beijing Chemical Company, China) were guaranteed reagents.

\subsection{Fish and exposure protocol}

Fish were cultured in 10-L aquaria. A batch of 11-month-old adult Japanese Medaka with mean values of $3.4 \mathrm{~cm}$ in length and $0.35 \mathrm{~g}$ in weight were pre-domesticated in a flow-through system. The water quality was controlled as follows: $\mathrm{pH}, 7.0-7.6$; oxygen concentration, 5-7 mg/L; hardness of $\mathrm{CaCO}_{3}, 200 \mathrm{mg} / \mathrm{L}$; conductivity, $650 \mu \mathrm{S} / \mathrm{cm}$; water temperature, $22-25^{\circ} \mathrm{C}$. All fish were fed twice a day with artemia and kept under a 12-h light and 12-h dark cycle.

In the acute toxicity study, three separate trials were performed using the same batch of Medaka. Adult fish (10 per group) were randomly administered to a graded series of sodium selenite and Nano-Se solutions for consecutive $48 \mathrm{~h}$. All fish were fasted during the acute exposure. Cumulative mortality within $48 \mathrm{~h}$ after exposure was used for the calculation of median lethal concentration $\left(\mathrm{LC}_{50}\right)$. Based on the $\mathrm{LC}_{50}$ values obtained from the acute toxicity test, suitable amount of selenite and Nano-Se were diluted with the stock solution using dechlorinated water and administrated to the experimental fish. Two replicates with 28 fish per group were conducted in the bio-kinetics and biomarkers experiments. All experimental fish were fed once a day and the exposure water was completely changed every day. Liver, gill, muscle, and whole body were collected on days 3, 5, 7, and 10. After exposure, the remaining fish were transferred and raised in clean water for an additional week for elimination experiments.

\subsection{Selenium content analysis}

Selenium content was detected following the method by He et al. (2002) with some minor modifications. Samples including fish tissues and exposure water were put into a PTFE digestion container. A portion of concentrated $\mathrm{HNO}_{3}(2 \mathrm{~mL})$ and $\mathrm{H}_{2} \mathrm{O}_{2}(30 \%, 1 \mathrm{~mL})$ were added into the containers, which were thereafter placed in stainless steel bombs and sealed with a screw closure to avoid any acid leakage. The assembly was then placed in an oven heated at $180^{\circ} \mathrm{C}$ for $8 \mathrm{~h}$. After cooling to room temperature, the containers were taken out of the bomb and placed on an electric stove without a cover and the temperature was maintained at $120^{\circ} \mathrm{C}$ until approximate $0.5 \mathrm{~mL}$ of solution remained. Subsequently, the residual solution $\left(\mathrm{Se}^{\mathrm{VI}}\right)$ was reduced to $\mathrm{Se}^{\mathrm{IV}}$ by adding $2 \mathrm{~mL}$ of $6 \mathrm{~mol} / \mathrm{L} \mathrm{HCl}$ and kept at $120^{\circ} \mathrm{C}$ for $30 \mathrm{~min}$. Finally, the remaining solution $(0.5 \mathrm{~mL})$ was diluted to $10 \mathrm{~mL}$ with $1.2 \mathrm{~mol} / \mathrm{L} \mathrm{HCl}$ for atomic fluorescence spectrophotometer (AFS-620, Beijing Ruili Analytical Instrument, Beijing, China) analysis. The optimized experimental parameters for AFS are listed in Table 1 . To validate the analytical method, the determination of
Table 1

Optimized experimental conditions for atomic fluorescence spectrophotometer (AFS)

\begin{tabular}{ll}
\hline Parameters & Optimized values \\
\hline Hydride generation & \\
$\mathrm{KBH}_{4}$ concentration & $2.0 \%(\mathrm{mPv})$ \\
$\mathrm{HC} 1$ concentration & $1.2 \mathrm{~mol} / \mathrm{L}$ \\
Sampling time & $5 \mathrm{~s}$ \\
Hydride generation time & $18 \mathrm{~s}$ \\
AFS & \\
Lamp & Hollow cathode lamp, $196.0 \mathrm{~nm}$ \\
PMT voltage & $300 \mathrm{~V}$ \\
Primary current & $60 \mathrm{~mA}$ \\
Carrier gas & Argon, $300 \mathrm{~mL} / \mathrm{min}$ \\
\hline
\end{tabular}

selenium was conducted in a certified reference material, Chinesepork liver (GBW08551), and the results $(0.96 \pm 0.17 \mu \mathrm{g} / \mathrm{g}, n=4)$ agreed well with the certified value $(0.94 \pm 0.03 \mu \mathrm{g} / \mathrm{g})$.

\subsection{Oxidative stress parameters}

All tests were conducted within 1 day after the pretreatment of tissues. According to results from preliminary experiments, we chose the optimized value of $1: 20(0.86 \% \mathrm{NaCl})$ as the dilution ratio. Liver samples were homogenized with ice cold $0.86 \% \mathrm{NaCl}$ and centrifuged at $8000 \mathrm{rpm}$ at $4{ }^{\circ} \mathrm{C}$ for $10 \mathrm{~min}$. The resulting supernatants were used for the determination of GPx, SOD, and GSH. GPx activity was assessed using hydrogen peroxide as a substrate (Wendel, 1981). This method is based on the oxidation of glutathione by hydrogen peroxide via glutathione peroxidase. SOD activity was measured using xanthine-xanthine oxidase and nitroblue tetrazolium (NBT). One unit of SOD is defined as the amount of protein that inhibits the rate of NBT reduction by $50 \%$ (Sun et al., 1988). GSH concentrations were determined using 5,5-dithionitrobenzoic acid (Ellman, 1959). Protein contents were assayed by the Bradford dyebinding assay with bovine serum albumin as standard (Bradford, 1976). The absorbances of GPx, SOD, GSH, and protein were respectively measured at 412, 550, 412, and $590 \mathrm{~nm}$ using a microtiter plate reader (DNA Expert, TECAN, Austria).

\subsection{Statistical analysis}

Mean values were calculated from the replicates and presented with standard deviation $(n=3-5)$. The normality and homogeneity of variance were checked out and a one-way analysis of variance (ANOVA) was then performed to assess the significance of differences. Differences were considered significant at $p<0.05$.

\section{Results}

\subsection{Se-sufficient fish}

Initially, we investigated whether the fish used in the present study were Se-sufficient or -deficient. After 7 days of exposure of selenite and Nano-Se at $100 \mu \mathrm{g}$ Se/L, a dose of approximately 200 -fold higher than the values provided by food source, Se concentrations in fish liver increased dramatically (Fig. 1A), while no increase in hepatic GPx activity was observed when compared to controls (Fig. 4A), which suggested that seleno-enzymes in the Medaka livers were saturated before Se supplementation and thus the tested fish were Se-sufficient. 

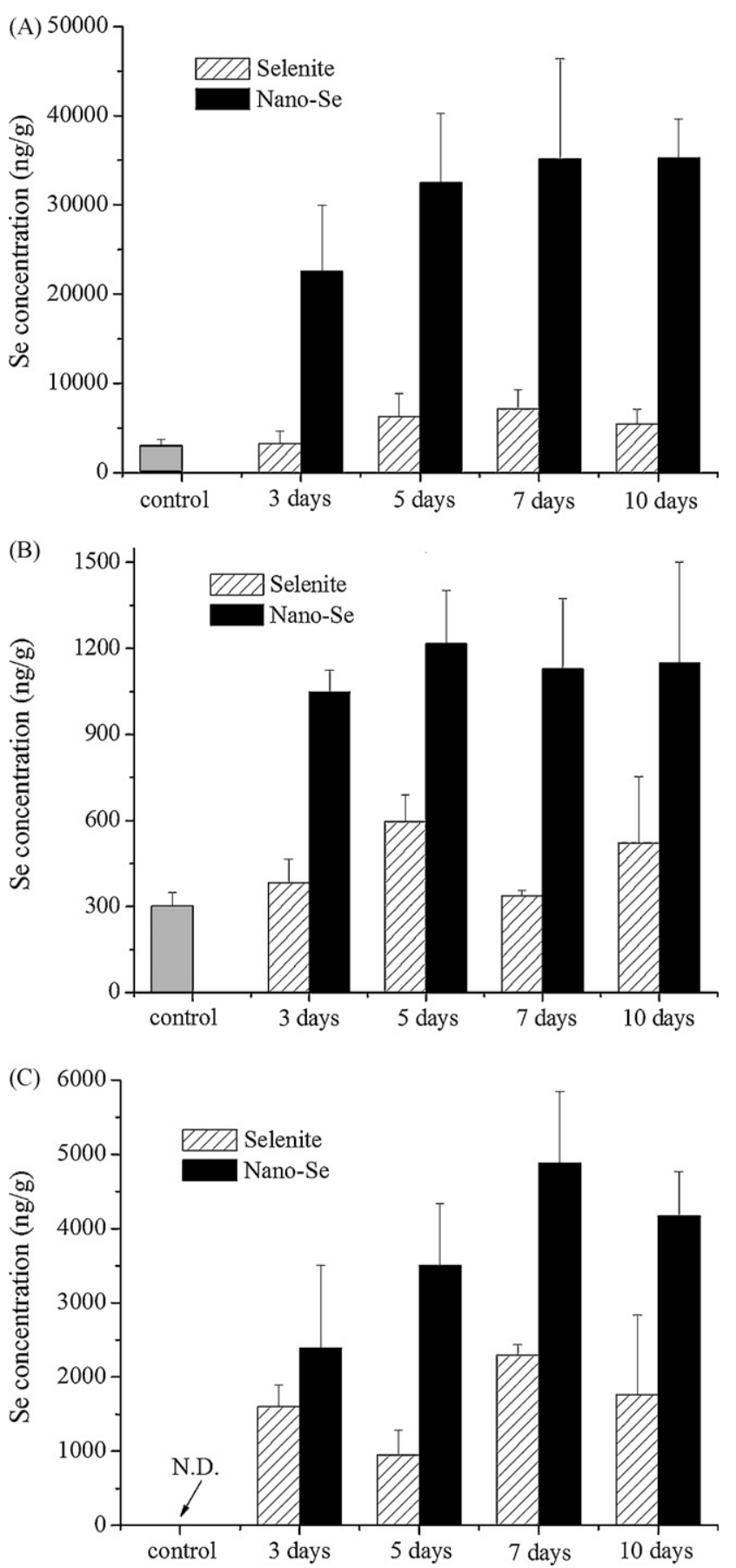

Fig. 1. Se concentrations in liver (A), muscle (B) and gill (C) of Medaka with the increase of exposure time. Data are expressed as means \pm S.D. $(n=4)$.

\subsection{Acute toxicity}

Zhang et al. (2005) observed that Nano-Se has lower acute toxicity when compared to selenite in mice based on $\mathrm{LD}_{50}$ values (113.0 vs. $15.7 \mathrm{mg} \mathrm{Se} / \mathrm{kg}$ body weight). In this study, we compared the response of Medaka to both Se forms. To our surprise, it was found that Nano-Se was more toxic than selenite in Medaka. Table 2 shows the mortality of Medaka after exposure to a graded series of Se solution for consecutive $48 \mathrm{~h}$. Nano-Se caused $100 \%$ mortality at $3.2 \mathrm{mg}$ $\mathrm{Se} / \mathrm{L}$. However, selenite caused only $10 \%$ mortality at $2.0 \mathrm{mg} \mathrm{Se} / \mathrm{L}$ and $80 \%$ mortality at $8.0 \mathrm{mg} \mathrm{Se} / \mathrm{L}$. The $48 \mathrm{~h} \mathrm{LC}_{50}$ of selenite and Nano-Se were calculated to be 4.7 and $1.0 \mathrm{mg} \mathrm{Se} / \mathrm{L}$, respectively.
Table 2

Mortality of Medaka after the exposure to sodium selenite and Nano-Se for $48 \mathrm{~h}$

\begin{tabular}{lcllc}
\hline Inorganic selenite & & & Nano-Se \\
\cline { 5 - 5 } \cline { 5 - 5 } Se dose $(\mathrm{mg} / \mathrm{L})$ & Mortality $(\%)$ & & Se dose $(\mathrm{mg} / \mathrm{L})$ & Mortality $(\%)$ \\
\hline 1 & 0 & 0.2 & 0 \\
2 & 10 & 0.4 & 10 \\
4 & 30 & 0.8 & 20 \\
8 & 80 & 1.6 & 80 \\
10 & 100 & 3.2 & 100 \\
\hline
\end{tabular}

\subsection{Bioaccumulation of $\mathrm{Se}$}

Based on the half lethal dose described above, $100 \mu \mathrm{g} \mathrm{Se} / \mathrm{L}$ solutions for both selenite and Nano-Se were selected to observe selenium accumulation in Medaka by kinetic analysis. The actual Se concentrations in water from the control, selenitetreated, and Nano-Se-treated groups were $4.9 \pm 1.0,103.4 \pm 1.3$, and $92.8 \pm 2.1 \mu \mathrm{g} \mathrm{Se} / \mathrm{L}$, respectively. Some minor loss of Se was likely due to adherence to the walls of the aquaria. In general, exposure concentrations of Se solutions were relatively stable. Fig. 1 shows the changes of Se concentrations in liver, gill and muscle of fish during the exposure. Both forms of Se species could effectively increase the selenium contents in these tissues. Surprisingly, Nano-Se caused hyper-accumulation of selenium in fish liver, which was sixfold higher than selenite. The bioconcentration factors (BCFs) of NanoSe and selenite in fish liver were 320 and 25, respectively. Animal studies have demonstrated that liver was the main target organ of Se toxicity (Diskin et al., 1979). High levels of Se accumulation (up to $35.3 \mathrm{mg} \mathrm{Se} / \mathrm{kg}$ ) in the liver exposed to Nano-Se may pose more serious threat to Medaka compared to the relatively lower levels of accumulation ( $5.5 \mathrm{mg} \mathrm{Se} / \mathrm{kg}$ ) induced by selenite. Moreover, NanoSe also caused more efficient accumulation of selenium in gills and muscles compared to selenite, with the differences ranging from two- to fourfold. It was also observed that Se could rapidly be taken up and kept at a stable state in fish tissues during exposure (Fig. 1), and no significant time-dependent response was observed.

\subsection{Clearance of Se}

The clearance kinetics of Se in whole bodies is shown in Fig. 2. After 7 days of depuration (E-7), decreased ratios of selenium concentrations in selenite-treated and Nano-Se-treated groups were

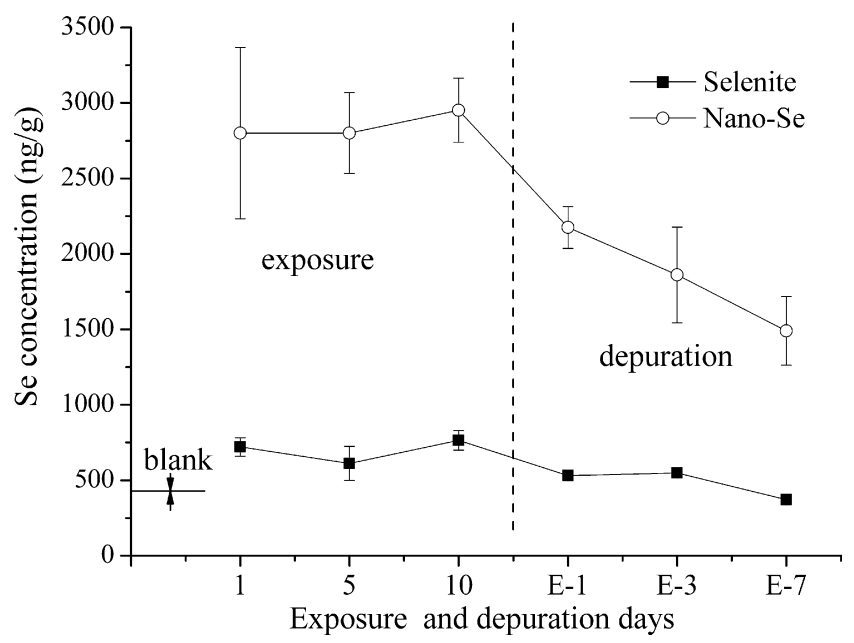

Fig. 2. Accumulation and clearance of Se in whole fish at exposure procedure (days 1, 5 and 10) and depuration stage (E1, E3 and E7). Values are expressed as means \pm S.D. of three fish per group. 


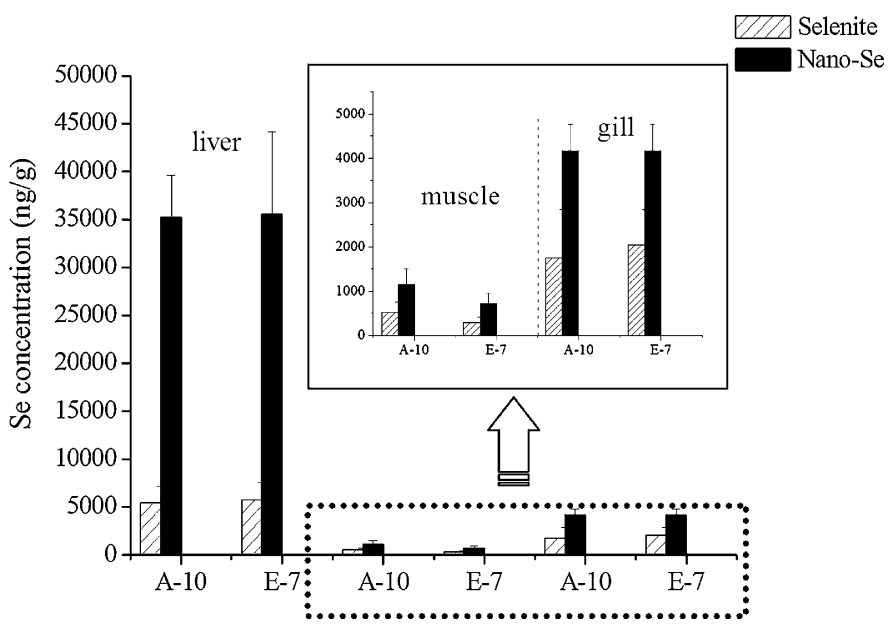

Fig. 3. Comparison of selenium concentrations after 10 days of exposure (A-10) and 7 days of depuration (E-7) in liver, muscle and gill tissues.

$51.4 \%$ and $49.5 \%$, respectively. This observation demonstrates that excessive selenium can be removed at the same extent via depuration, irrespective of the type of Se forms (selenite or Nano-Se).

The persistence of superfluous Se in tissues such as liver, gill, and muscle was also investigated. Se concentrations after 7-day depuration (E-7) were compared with those after 10 days of exposure (A-10). After 7 days of depuration, Se concentrations in muscles reduced to some extent ( $42.5 \%$ for selenite and $36.5 \%$ for Nano-Se), while Se in livers and gills did not decrease significantly (Fig. 3 ). The long-term persistence of Se in livers and gills, which was caused by high absorption and low clearance, resulted in the final hyperaccumulation of selenium and the corresponding toxicities.

\subsection{Oxidative stress biomarkers}

To estimate the potential impacts of hyper-accumulation of different Se forms in the liver of the fish, several hepatic antioxidant enzymatic activities including GPX, SOD and GSH were monitored after 7 days of exposure at $100 \mu \mathrm{g}$ Se/L. The seleno-enzyme GPx was not found to be upregulated by Nano-Se or selenite, suggesting that selenium concentrations were already saturated in the livers (Fig. 4A). As shown in Fig. 4B, the hepatic SOD activity was markedly inhibited by both selenite $(p<0.05)$ and Nano-Se $(p<0.01)$, in which Nano-Se showed more potent inhibitory effects than selenite at the same exposure dose $(p>0.05)$. With respect to GSH, Nano-Se evidently increased hepatic GSH concentrations compared to the control $(p<0.05)$, while selenite did not have any apparent influence on the GSH levels (Fig. 4C).

\section{Discussion}

Selenium, as an essential micronutrient in animals, has three levels of biological activities: (1) trace levels are required for normal growth and development; (2) nutritional and supranutritional levels can be stored and homeostatic functions maintained; and (3) toxic levels can result in deleterious effects (Hamilton, 2004). Since the margin between salutary and toxic effects of selenium is very narrow, safety margin and potential toxic effects are important questions to be addressed when consider the role of selenium in dietary supplements. In recent years, the selenium criteria for aquatic life and the proposed toxicity thresholds have become a controversial topic (Chapman, 1999; DeForest et al., 1999; Fairbrother et al., 1999). Some researchers have suggested a dietary selenium toxicity threshold value of 3-4 $\mu \mathrm{g} \mathrm{Se/g}$ (Maier and Knight,
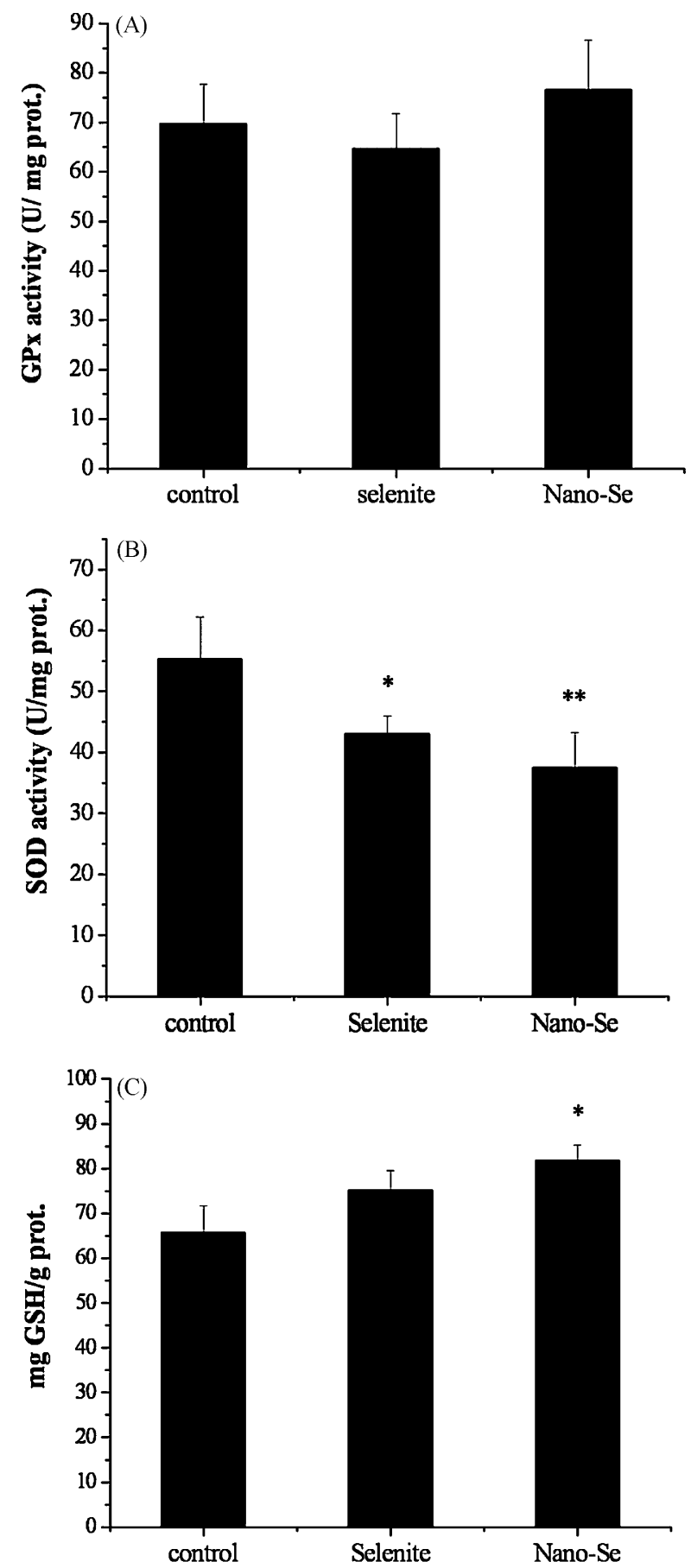

Fig. 4. Effects of selenite and Nano-Se on GPx activity (A), SOD activity (B), and GSH level (C) after 7 days of exposure at the dose of $100 \mathrm{Se} \mu \mathrm{g} / \mathrm{L}$ in Medaka livers compared to the control group. Values are expressed as means \pm S.D. of five fish per group. ${ }^{*} p<0.05$ and ${ }^{* *} p<0.01$.

1994), which is comparable to the selenium concentration in fish food used in our experiment $(1.57 \pm 0.03 \mu \mathrm{g}$ Se/g dw). For long-term water exposure, most researchers have proposed selenium toxicity thresholds values of $2-5 \mu \mathrm{g} \mathrm{Se} / \mathrm{L}$ (Henderson et al., 1995; USDOI, 1998). In the short-term toxicity study herein, Se bioavailability and subsequent toxicological effects were investigated at a concentration of $100 \mu \mathrm{g} \mathrm{Se} / \mathrm{L}$ for the evaluation of potential hazards caused by superabundant Se exposure.

Evidences revealed that the $96 \mathrm{~h}$ selenite $\mathrm{LC}_{50}$ for juvenile rainbow trout ranged from 4.2 to $9.0 \mathrm{mg} \mathrm{Se} / \mathrm{L}$ (Hodson et al., 1980; Buhl 
and Hamilton, 1991), which is similar to the results of our experiments ( $4.67 \mathrm{mg} \mathrm{Se} / \mathrm{L}$ of $48 \mathrm{~h} \mathrm{LC}_{50}$ ). Zhang et al. (2005) concluded that Nano-Se had lower acute toxicity when compared with selenite in mice, however, the potential toxicity of Nano-Se has not been investigated in aquatic animals. In our study, we found that Nano-Se was more toxic than selenite for Medaka, and the value of the $48 \mathrm{~h}$ $\mathrm{LC}_{50}$ of Nano-Se was fivefold lower than that of selenite. Further experiments clearly indicated that selenium bioaccumulation in selected tissues at our prescribed exposure concentration $(100 \mu \mathrm{g}$ $\mathrm{Se} / \mathrm{L}$ ) was dramatically higher for groups treated with Nano-Se than those treated with selenite. Variations in animal models and exposure routes likely contributed to differences between our results in fish and previous results in mice.

\subsection{Se bioavailability}

Selenium bioavailability has been studied in several species of fish, including rainbow trout (Vidal et al., 2005), salmon (Lorentzen et al., 1994) and juvenile grouper (Lin and Shiau, 2005). Selenomethionine has been reported to have higher bioavailability than sodium selenite for Atlantic salmon (Lorentzen et al., 1994) and channel catfish (Wang and Lovell, 1997). Based on our analysis of the bioaccumulation and clearance of Se, we unequivocally conclude that both Nano-Se and sodium selenite can be biomagnified in adult Medaka fish. Previous studies have reported that accumulation of Se was higher in mice-treated with SeMet than in mice-treated with Nano-Se (Zhang et al., 2008), and the bioavailability of organic forms of Se (selenomethionine) was higher than that of inorganic forms of Se (sodium selenite) (Levander, 1983; Smith and Picciano, 1987). These discrepancies may be the result of the differences in lipophilic properties and metabolic pathways of the Se species.

A basic understanding of the absorption, distribution, and clearance of different Se forms can be used to determine Se assimilation efficiencies and excretion rates, which in turn can be applied to forecast long-term, steady-state tissue selenium levels (Baines et al., 2002). In our elimination experiments, the Se clearance rate in the whole body of Medaka over 7 days was $2.34 \mu \mathrm{g} \mathrm{Se} /(\mathrm{kg} \mathrm{h})$ for selenite (Fig. 2), which is comparable to previous report that average Se urinary excretion rate over $48 \mathrm{~h}$ was $2.19 \mu \mathrm{g} \mathrm{Se} /(\mathrm{kg} \mathrm{h})$ in sturgeon orally dosed with $1000 \mu \mathrm{g} \mathrm{Se} / \mathrm{kg}$ (Tashjian and Hung, 2006). In contrast, the higher clearance rates in the whole body of fish exposed to Nano-Se showed a nearly fourfold depression $(8.70 \mu \mathrm{g} \mathrm{Se} /(\mathrm{kg} \mathrm{h}))$ compared to that of inorganic selenite, which is likely caused by decreased amounts of Se incorporated into proteins of fish exposed to Nano-Se. Unexpectedly, no apparent decreases of Se in the liver and gill after 7 days of depuration were observed (Fig. 3). For liver, an alternative explanation may be the steady and strong binding of Se into proteins by virtue of the first-pass effect. With respect to gill, it has large surface and a great number of capillary vessels that participate in the blood circulatory system. Moreover, blood Se concentrations have been observed to be near maximal concentrations at the end of a 48-h postintubation period (Tashjian and Hung, 2006), which could interpret the fact that Se concentrations in gill were still high after 7 days of depuration. Our results provide evidences that superfluous selenium can be removed through excretion with a high clearance rate. The decrease of Se in whole body of fish regardless of exposure to selenite or Nano-Se might be a homeostatic response to the higher levels of intake Se, which also indicated the importance of Se homeostasis to organisms (Sunde, 2001).

\subsection{Oxidative stress}

Due to the consequence of hyper-accumulation of selenium in liver and the fact that Se generated reactive oxygen species (ROS) was one of the major mechanisms for Se toxicity (Spallholz et al., 2004), several hepatic oxidative stress indicators were determined after exposure to $100 \mu \mathrm{g}$ Se/L sodium selenite and Nano-Se for 7 days. Se-dependent GPx is the most important peroxidase for the detoxification of hydroperoxides, and the activities of GPX have been widely used as biomarkers for assessing Se status in humans and animals (Neve, 1995). Moreover, the determination of GPx activity has been shown to be an effective way to estimate the bioavailability of Se in vivo (Favier, 1993). In our studies, exposure to selenite and Nano-Se at $100 \mu \mathrm{g}$ Se/L for 7 days resulted in no enhancement of GPx activity suggesting that Se was saturated and that the fish were not Se-deficient. SOD and GSH were also used as indicators of oxidative stress. SOD is the first enzyme to deal with oxyradicals and catalyzes the transformation of superoxide radicals to $\mathrm{H}_{2} \mathrm{O}_{2}$ and $\mathrm{O}_{2}$ (Kappus, 1985), and GSH is a major sulfhydryl compound with low molecular weight that acts as a protective reagent against numerous toxic substances through the -SH group (Stryer, 1988). Our results showed that both of Nano-Se and selenite significantly decreased hepatic SOD activity of Medaka (Fig. 4B). Furthermore, Nano-Se exhibited more inhibitory effects than selenite at the same Se dosing although no statistical differences were observed. Simultaneously, the hepatic GSH concentrations were significantly increased by Nano-Se at $100 \mu \mathrm{g}$ Se/L $(p<0.05)$ while no apparent alteration of GSH level was observed with selenite (Fig. 4C). These results differed from previous reports (Zhang et al., 2005) that Nano-Se had a weaker interference effect than selenite on antioxidative balance in Se-deficient mice. In general, our experiment revealed that Nano-Se exhibited more potent effects on disturbances to the antioxidant defense systems in Medaka fish compared to inorganic selenite, which is likely a consequence of hyper-accumulation of selenium.

\section{Conclusions}

Based on the fact that selenium toxicity depended not only on the selenium status and the quantity of the element consumed but also on its chemical forms, several biological effects between Nano-Se and sodium selenite to Medaka fish were compared in the present study. Our results indicate that the toxicity of Nano-Se is higher than that of selenite based on $\mathrm{LC}_{50}$ values. Hyper-accumulation and slow clearance of Se in Medaka may be the reasons of high toxicity of Nano-Se. Unlike previous studies where low toxicity of Nano-Se was observed in mice and rats, the opposite conclusion was drawn from the fish assay. The toxicity of nanomaterials was found to be more complicated than expected, which offered the present investigation of significance in both fundamental research and practical applications of nanomaterials. Further supportive and extensive researches are warranted.

\section{Acknowledgements}

This work was jointly supported by the National Natural Science Foundation of China (20537020), and Chinese Academy of Sciences (KZCX2-YW-420-21). The authors are thankful to Adina Shiang Chuang for the critical comments in the revision of the manuscript.

\section{References}

Albrecht, M.A., Evans, C.W., Raston, C.L., 2006. Green chemistry and the health implications of nanoparticles. Green Chem. 8, 417-432.

Baines, S.B., Fisher, N.S., Stewart, R., 2002. Assimilation and retention of selenium and other trace elements from crustacean food by juvenile striped bass (Morone saxitilis). Limnol. Oceanogr. 47, 646-655.

Bradford, M., 1976. A rapid and sensitive method for the quantification of microgram quantities of protein utilizing the principle of protein-dye binding. Anal. Biochem. 72, 248-254. 
Buhl, K.J., Hamilton, S.J., 1991. Relative sensitivity of early life stages of arctic grayling, coho salmon, and rainbow trout to nine inorganics. Ecotox. Environ. Safe 22, 184-197.

Chapman, P.M., 1999. Selenium-a potential time bomb or just another contaminant? Hum. Ecol. Risk Assess. 5, 1123-1138.

Clark, R.F., Strukle, E., Williams, S.R., Manoguerra, A.S., 1996. Selenium poisoning from a nutritional supplement. J. Am. Med. Assoc. 275, 1087-1088.

DeForest, D.K., Brix, K.V., Adams, W.J., 1999. Critical review of proposed residuebased selenium toxicity thresholds for freshwater fish. Hum. Ecol. Risk Assess. 5, 1187-1228.

Diskin, C.J., Tomasso, C.L., Alper, J.C., Glase, M.L., Fliegel, S.E., 1979. Long-term selenium exposure. Arch. Intern. Med. 139, 824-826.

Eisler, R., 2000. Selenium Handbook of Chemical Risk Assessment: Health Hazards to Humans, Plants, and Animals, vol. 3. Lewis Publishers, CRC Press, Boca Raton, FL, pp. 1649-1705.

Ellman, G.L., 1959. Tissue sulfhydryl groups. Arch. Biochem. Biophys. 82, 70-77.

Fairbrother, A., Brix, K.V., Toll, J.E., McKay, S., Adams, W.J., 1999. Egg selenium concentrations as predictors of avian toxicity. Hum. Ecol. Risk Assess. 5, 1229-1253.

Favier, A.E., 1993. Nutritional and clinical factors affecting the bioavailability of trace elements in humans. In: Schulemmer, U. (Ed.), Bioavailability, vol. 93. Ettlingen, Germany, pp. 202-211.

Gasmi, A., Garnier, R., Galliot-Guilley, M., Gaudillat, C., Quartenoud, B., Buisine, A. Djebbar, D., 1997. Acute selenium poisoning. Vet. Hum. Toxicol. 39, 304-308.

Hamilton, S.J., 2004. Review of selenium toxicity in the aquatic food chain. Sci. Total Environ. 326, 1-31.

He, B., Liang, L.N., Jiang, G.B., 2002. Distributions of arsenic and selenium in selected Chinese coal mines. Sci. Total Environ. 296, 19-26.

Henderson, J.D., Maurer, T.C., Schwarzbach, S.E., 1995. Assessing Selenium Contamination in Two San Joaquin Valley, California sloughs. Draft Report to the US Fish and Wildlife Service, Region 1. Division of Environmental Contaminants, Sacramento, CA, p. 19.

Hilton, J.W., Hodson, P.V., Slinger, S.J., 1980. The requirement and toxicity of selenium in rainbow trout (Salmo gairdneri). J. Nutr. 110, 2527-2535.

Hodson, P.V., Spry, D.J., Blunt, B.R., 1980. Effects on rainbow trout (Salmo gairdneri) of a chronic exposure towaterborne selenium. Can. J. Fish. Aquat. Sci. 37, 233-240.

Kappus, 1985. Lipid peroxidation: mechanisms, analysis enzymology and biological relevance. In: Sies, H. (Ed.), Oxidative Stress. Academic Press, London, pp. 273-310.

Klasing, K.C., 1998. Comparative Avian Nutrition. Oxford University Press, New York.

Levander, O.A., 1983. Considerations in the design of selenium bioavailability studies. Fed. Proc. 1, 1721-1725.

Lin, Y.H., Shiau, S.Y., 2005. Dietary selenium requirements of juvenile grouper Epinephelus malabaricus. Aquaculture 250, 356-363.

Lorentzen, M., Maage, A., Julshamn, K., 1994. Effects of dietary selenite or selenomethionine on tissue selenium levels of Atlantic salmon (Salmo salar). Aquaculture $121,359-367$.
Maier, K.J., Knight, A.W., 1994. Ecotoxicology of selenium in freshwater systems. Rev. Environ. Contam. Toxicol. 134, 31-48.

Neve, J., 1995. Human selenium supplementation as assessed by changes in blood selenium concentration and glutathione peroxidase activity. J. Trace Elem. Med. Biol. 9, 65-73.

Patching, S.G., Gardiner, P.H.E., 1999. Recent developments in Se metabolism and chemical speciation: a review. J. Trace Elem. Med. Biol. 13, 193-214.

Smith, A.M., Picciano, M.F., 1987. Relative bioavailability of selenocompounds in the lactating rat. J. Nutr. 117, 725-731.

Spallholz, J.E., Palace, V.P., Reid, T.W., 2004. Methioninase and selenomethionine but not Se-methylselenocysteine generate methylselenol and superoxide in an in vitro chemiluminescent assay: implications for the nutritional carcinostatic activity of selenoamino acids. Biochem. Pharmacol. 67, 547-554.

Stryer, 1988. Biochemistry, 3rd ed. Freeman WH, New York.

Sun, Y., Larry, W., Oberley, W., Ying, L., 1988. A simple method for clinical assay of superoxide dismutase. Clin. Chem. 34, 497-500.

Sunde, R.A., 2001. Selenium. In: Bowman, B.A., Russell, R.M. (Eds.), Present Knowledge in Nutrition, 8th ed. ILSI, Washington, DC, USA, pp. 352-365.

Tashjian, D.H., Hung, S.S.O., 2006. Selenium absorption, distribution, and excretion in white sturgeon orally dosed with L-selenomethionine. Environ. Toxicol. Chem. 25, 2618-2622.

USDOI (US Department of the Interior), 1998. Guidelines for interpretation of the biological effects of selected constituents in biota, water, and sediment. National Irrigation Water Quality Program Information Report No. 3, Denver, CO.

Vidal, D., Bay, S.M., Schlenk, D., 2005. Effects of dietary selenomethionine on larval rainbowtrout (Oncorhynchus mykiss). Arch. Environ. Contam. Toxicol. 49, 71-75.

Wang, C., Lovell, R.T., 1997. Organic selenium sources, selenomethionine and selenoyeast, have higher bioavailability than an inorganic selenium source, sodium selenite, in diets for channel catfish (Ictalurus punctatus). Aquaculture $152,223-234$.

Wang, H.L., Zhang, J.S., Yu, H.Q., 2007. Elemental selenium at nano size possesses lower toxicity without compromising the fundamental effect on selenoenzymes: comparison with selenomethionine in mice. Free Radic. Biol. Med. 42, 1524-1533.

Wendel, A., 1981. Glutathione peroxidase. Methods Enzymol. 77, 325-333.

Zhang, J.S., Gao, X.Y., Zhang, L.D., Bao, Y.P., 2001. Biological effects of a nano red elemental selenium. Biofactors 15, 27-38.

Zhang, J.S., Wang, H.L., Yan, X.X., Zhang, L.D., 2005. Comparison of short-term toxicity between Nano-Se and selenite in mice. Life Sci. 76, 1099-1109.

Zhang, J.S., Wang, X.F., Xu, T.W., 2008. Elemental selenium at nano size (NanoSe) as a potential chemopreventive agent with reduced risk of selenium toxicity: comparison with Se-methylselenocysteine in mice. Toxicol. Sci. 101, 22-31. 